\title{
The Impact of Negotiation as a Social Practice on EFL Writing Peer Assessment Sessions
}

\author{
Talal Alqarni \\ English Language Institute, King Abdulaziz University, Saudi Arabia \\ Abdullah Alshakhi \\ English Language Institute, King Abdulaziz University, Saudi Arabia
}

\begin{abstract}
This qualitative study aims to investigate the negotiation technique that EFL students employ in EFL writing peer assessment sessions. As a data collection instrument, a close-observation has been used for $(n=20)$ participants randomly selected from an intermediate school in Saudi Arabia. The purpose of using observation is to shed light on the students' negotiation of peer assessment practices in writing class and how they work collaboratively in order to discuss their writing prompts more effectively. The findings of the study showed that students' negotiations skills impacted improvements of the writing skill positively. Moreover, negotiations and discussions have actively engaged students into effective collaborative learning and considerably increased their participation and language practice in their peer assessment sessions.
\end{abstract}

Index Terms—negotiation, EFL writing assessment, peer assessment, Saudi EFL context, ZPD

\section{INTRODUCTION}

Writing assessment has always been considered a very complex issue in ESL/EFL classes (Crusan, 2002; Huang, 2009). There are always debates about some issues regarding writing assessment, such as scoring writing performance, reliability, and validity of writing assessment tools. In addition to those issues, raters are often concerned about the scales of exemplary texts, how those scales are constructed, and what linguistics aspects should be included in them (Hamp-Lyons, 1990; Knoch, 2011; Alshakhi, 2019). In the Saudi context, writing assessment has hardly ever been a subject of agreement amongst practitioners, instructors, or even students for many years (Obeid, 2017; Alshakhi, 2018). Its complexity represents a challenge for many writing teachers. The learning outcomes are often affected by assessment tools that teachers use in class which are, in general, based on their belief and theoretical background (Hyland, 2019). Moreover, there are many challenges that play a very significant role in imposing some assessment methods in the class. Those challenges such as large classes, demotivated students, teachers' pre-service training, and lack of teachers' professional development have been a concern of many Saudi scholars (Elyas \& Al Grigri, 2014). For example, the massive number of students in the class puts a heavy burden on teachers which often impels them to resort to traditional assessment methods, such as testing or holistic grading to assess students' writing performance (Bahanshal, 2013).

Alternative assessment has emerged as a suggested tool to overcome those challenges in many educational contexts. It has been argued that it enables teachers to vary their assessment tools according to their contexts and gives them the ability to overcome many assessment challenges. Tannenbaum (1996) stated that "many educators have come to recognize that alternative assessments are an important means of gaining a dynamic picture of students' academic and linguistic development" (p.2).

One of the key aspects of alternative assessment tools that might be used to assess students' writing performance is peer assessment. The practice of peer assessment as an alternative writing assessment tool has grown in the field of L1 and ESL/EFL writing teaching since the 1990s and became one of the most effective assessment tools in ESL/EFL contexts (Min, 2006, 2016; Hyland, 2019). Many scholars advocate the use of peer assessment in ESL/EFL writing classes for its potential advantages for learners. They claim that peer assessment can foster students' writing skills and can prove to be an effective tool in raising students' self-confidence, awareness of assessment, and critical thinking. Additionally, it can save teachers' time and reduce assessment load when appropriately used in large classes. On the other hand, the opponents claim that ESL/EFL students are not often capable of conducting effective and fair peer assessment due to their low proficiency level, the tendency for friendship bias, and the complexity of peer-assessment techniques. They also claim that when students conduct peer assessment, they often negotiate the low order concerns of writing rather than the high order concerns and deep writing concepts, such as arguments, perspectives, and critical thinking (Saito \& Fujita, 2004; Bijami et al., 2013). As a result, learning outcomes are compromised.

Although many studies have examined the effectiveness of peer assessment techniques, little attention has been given to this notion in the Saudi EFL context, except for two studies which were conducted on university-level students. Therefore, this study targets a public school's students to shed light on the negotiation of peer assessment practice and its effect on students' attitudes towards writing in the Saudi context. As a sub-goal, this study seeks to investigate how 
the ZPD contributes to stimulating negotiation and interaction among EFL students in the Saudi context.

\section{THEORETICAL FRAMEWORK}

It's important to note that the theoretical framework of this study has been chosen to discuss how negotiation in writing peer assessment sessions might impact the learning process in the writing skill. In the following section, I will discuss the theatrical framework.

\section{The Zone of Proximal Development}

Based on the social constructivist theory, Vygotsky developed the notion of Zone of Proximal Development (ZPD), which is "the distance between the actual developmental level as determined by independent problem solving and the level of potential development as determined through problem solving under adult guidance or in collaboration with more capable peers" (Vygotsky, 1978, p. 86). Vygotsky assumes that there is a zone between what a learner can do and what $\mathrm{s} / \mathrm{he}$ cannot do. He asserts that a learning process should fill that zone with challenging activities to gradually move students from their actual developmental level to the potential developmental level through scaffolding, interaction, communicative activities, and collaboration with more capable peers that help them enhance their skills gradually (Wertsch, 1984; cited in Doherty, 2002; Khaliliaqdam, 2014; Hyland, 2019).

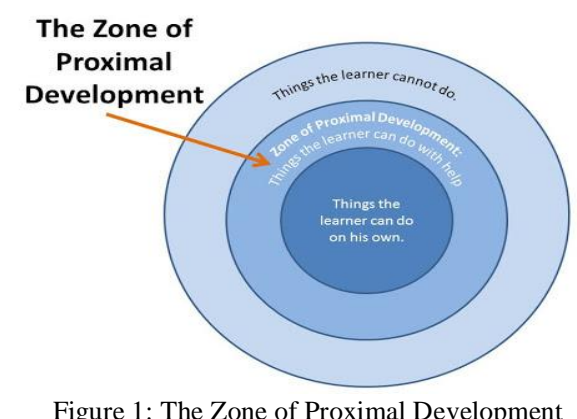

Since writing is a social practice, negotiation and interaction are considered the core of the ESL/EFL learning process in writing skill that contributes to the learners' writing development. Hence, many studies suggest implementing the Zone of Proximal Development (ZPD) theory to stimulate negotiation, interaction and reinforce the use of the language among ESL/EFL students, especially in a writing class. ZPD-based learning can be implemented in ESL/EFL contexts through various methods and strategies, such as active learning, cooperative learning, problem solving, and peer assessment which all boost negotiation and interaction between learners in a classroom environment.

\section{LITERATURE REVIEW}

Teaching and assessing writing in contexts where English is taught as a foreign language (EFL) is quite different from contexts where English is considered as the second language (ESL). Hence, there have been many attempts in the EFL and the Saudi context to understand writing assessment practices in general and peer assessment practices in particular. In the following sections, several studies are reviewed and discussed in detail.

\section{A. Impact of Peer Assessment on Writing}

Until recently, traditional tools of assessment are the most used tools in different parts of the world and testing is the dominant tool, especially in countries where English is taught as a foreign language, such as in the Arab world (Grami, 2010). However, moving towards new ESL/EFL teaching methods and strategies required new tools for assessment which led to the emergence of alternative tools including, but not limited to, portfolios, authentic assessments, group projects, and peer assessment. Alternative assessment helps gather data about students' progress and learning process (Coombe et al., 2012).

Many scholars have globally conducted many studies to investigate the effectiveness of alternative assessment, particularly peer assessment in ESL/EFL writing classes. Yusof et al. (2012) conducted action research in Bandung, Indonesia, to investigate the use of peer assessment at the planning stage of the writing process. Questionnaires, observations, writing samples, and interviews have been used as data collection tools for the study. The findings revealed that students with guidance from teachers were able to provide constructive feedback to their peers. That definitely essentializes the importance of effective negotiations in peer assessment sessions.

In the same line, Uymaz (2019) conducted another study in the Turkish context during the 2017-2018 academic year. His quantitative study aimed to find the effects of peer feedback on EFL students' written performances in essay writing. As for the participants of the study, a group of students $(n=8)$ took part in the study. Data was gathered from students' work samples. During an eight-week period, students were required to submit two drafts after receiving peer feedback on four separate essay tasks. Moreover, a pre-test and post-test were administered to students. Using Conrad and Goldstein's (1999) taxonomy, data collected from the correct revisions in the second drafts were calculated. Also, data 
coming from the pre-tests and the post-tests were statistically analyzed with SPSS by conducting a paired samples t-test. The findings showed that peer feedback helped students write $69 \%$ of the feedback points which have been provided by their peers correctly. In addition, the written test results showed a statistically significant difference between the pre-test and the post-test.

On the other hand, another study carried out by Huisman et al. (2018) aimed to compare the writing performance of undergraduate students who had provided or received anonymous written peer feedback in the context of academic writing. The findings revealed that there is no significant difference between giving and receiving feedback, and that both have resulted in similar improvements in writing performance. Moreover, results revealed that there is no direct relationship between peer feedback perceptions and writing performance improvement.

In the Saudi context, Alqurashi (2009) conducted a study on Saudi college students to investigate their perceptions towards using non-traditional strategies of feedback in writing class. Students were required to comment on each other's writing as peer assessment. To collect the data, 24 students responded to a four-point survey. The findings showed that most students reported that learning writing as a process had improved their writing skills. Moreover, results revealed that most students had a positive attitude towards both giving and receiving feedback from their peers which contributed to enhancing their compositions.

Another interesting study in the Saudi context conducted by Grami (2010) aimed to investigate the effectiveness of introducing peer assessment to a group of university-level students. Many data collection tools were used during the three-month-long project. Study findings showed that peer feedback had a great impact on the students. They were highly impressed by the potential of peer sessions on their English writing routines which has resulted in their eagerness to have more similar sessions in the future. Furthermore, results revealed that peer assessment has actively engaged students into effective cooperative learning and enhanced their participation in the class. According to the study's results, Grami claims that if there is more training for students to use peer feedback, the benefits might be very significant. It should be noted that Grami's study was conducted on the university-level students, which means that the effectiveness of peer assessment has not been investigated in primary and intermediate contexts.

Although there are interesting studies that have been done globally and in the Saudi context, peer assessment has to be studied in other neglected contexts, such as in public schools, especially in the primary and intermediate stages to investigate the effectiveness of using peer assessment as an assessment tool.

\section{B. Pros \& Cons of Peer Assessment}

Despite the increasing spread of alternative assessment in EFL/ESL classrooms, its effectiveness has not been determined as literature suggests divergent opinions on this issue. Peer assessment is one of those tools which might have many cons besides its pros. According to the literature, there are many advantages of using peer assessment as it actively involves students into the learning process. It also encourages students and motivates them to participate in classroom activities and negotiate relevant activities which create a conducive learning environment (Hyland, 2000). Similarly, peer assessment minimizes time spent on assessing students' work and reduces teachers' workloads (Yarrow \& Topping, 2001). In addition, peer assessment raises students' awareness of the assessment criteria, builds their selfconfidence, and promotes learner autonomy. One of the major benefits is that peer assessment helps develop critical thinking and social interaction among learners (Yang et al., 2006), and allows them to practice and develop the targeted language (Lundstrom \& Baker, 2009). On the other hand, one of the most significant issues that might affect the validity and the reliability of conducting peer assessment inside the writing class is the Friendship-bias. It has been argued that a relationship between students might affect the process of peer assessment and result in a tendency of friendship-bias (Saito \& Fujita, 2004; Lee et al., 2013). Moreover, Storch (2005) states that peer assessment might turn the focus of students to the product rather than the writing process. He also claims that many students' feedback often focuses on sentence-level mistakes and their notes might not be helpful for their peers.

Although there are rudimentary issues with the use of peer assessment as an assessment tool, the evidence suggests that the pros outweigh the cons which justify the use of peer assessment for effective and useful writing assessment.

\section{Elements of Successful Peer Assessment}

Min $(2005,2006)$ asserts the importance of peer assessment training before conducting it (i.e., students should be prepared for peer assessment by exposing them to its meaning, goal, and the expected benefit). Most often, peer assessment takes the form of formative assessment; thus, it may not be graded at the beginning, which can motivate students and develop their positive attitude towards peer assessment.

Successful peer assessment must have a rational concept. The conceptual rationales for peer assessment are to engage learners in the assessment process, to give them a role in their own learning, and to shift the responsibility for their learning to them, so they become autonomous learners (Liu \& Carless, 2006). During peer assessment, students might need support from their teachers, hence, teachers' observation or monitoring is very significant for successful peer assessment as they might help students introduce some critical notes about peers' works, train them how to respond to those critical notes with justifications and prepare a good atmosphere for students' negotiation. Therefore, teachers' following up and supporting students during peer assessment is very important for a successful peer assessment process (Finn \& Garner, 2011). Moreover, simple checklists or rubrics are very important for the peer assessment process, especially for low performing students who find conducting peer assessment a challenging task. 
Successful peer assessment totally depends on the effectiveness of feedback and the quality of negotiation and interaction among students. Black and William (1998) identify four elements for effective feedback which are: 1) designing accredited and measurable checklists or rubrics; 2) a means for identifying learners' performances in relation to those checklists or rubrics; 3) a means for comparing learners' performance to those checklists or rubrics; and 4) a mechanism in which the data can be applied to modify the gap.

\section{Appropriateness of Peer Assessment for Low Performing Students}

Low performing students might form the majority of ESL/EFL students in many contexts, particularly in the Arab world. Having low performing students in ESL/EFL classes affects the teaching process and the learning process as well. Since assessment is a part of the teaching process, it is also affected by the performance level of the students in the class. Thus, teachers often struggle to design appropriate activities and assessment tasks for those students. Implementing peer assessment for low performing students might be, to some extent, complicated for many reasons. Firstly, low performing students might reject the idea of conducting peer assessment. Secondly, the benefits of peer assessment might not be understood by the students. Finally, low performing students could find difficulty reading their peers' works critically. However, good observation and support from teachers might help overcoming these challenges, such as providing them with checklists or simple rubrics might be very effective at the beginning.

\section{E. Negotiation in Writing Peer Assessment Sessions}

Many scholars assert that learning is a social activity that is strongly influenced by involvement, engagement, and participation. It has also been argued that a language is a functional tool that can be acquired through interaction and negotiation in the classroom which play a very significant role in mediating learning (Krashen, 1982; Kramsch, 1986; Walsh, 2011, 2013, 2014; Urmeneta \& Walsh, 2017). Likewise, Walsh (2011) claims that Classroom Interaction Competence (CIC) is the core of the learning process. He defines CIC as "Teachers' and learners' ability to use interaction as a tool for mediating and assisting learning" (p.158). Consequently, negotiation and interaction are considered key to a successful learning process in writing classes, which can occur between teacher-student or studentstudent in a classroom environment. It can also take place during the writing peer assessment sessions to facilitate learning for students which lead to students' writing achievement.

As many of the contemporary practices in ESL/EFL classrooms advocate student-centered teaching, peer assessment derives its strength from the social learning theory of Vygotsky (Vygotsky, 1978). Peer assessment sessions mainly depend on the interaction and negotiation between learners which might include, exchanging ideas, critical thinking, and cognitive processes. Hence, peer assessment is one of those assessment tools that can help stimulate negotiation and interaction between students in the classroom. It can also help learners cooperate, negotiate with each other, and engage into social activities, such as dialogues and communicative activities to learn the language. During peer assessment sessions, students speak, listen, and negotiate which is a very realistic context for learning L2. Peer assessment is an authentic tool for learning due to its social characteristics.

\section{Research Question}

This study aims to answer the following overarching question:

1. How do language learners negotiate the practice of peer assessment in a writing class in the Saudi EFL context?

\section{METHODOLOGY}

This section discusses the methodology of this study: research design, context, participants, data collection instruments, data analysis methods, and ethical considerations.

\section{A. Research Design}

Bearing in mind that the research question of this study is: How do language learners negotiate the practice of peer assessment in a writing class in the Saudi EFL context? This study adopted a qualitative research design in order to examine my context and address its problems while considering factors that might affect it.

\section{B. Context and Participants}

The context of the study was an intermediate school located in Jeddah, in the western region of Saudi Arabia. The school is a public school under the management of the Saudi Ministry of Education. Like all public schools in the Saudi context, this school teaches English as a foreign language. Due to the limitations of the study which have been explained in detail in the limitations section, the participants of the study were $(n=20) 9$ th-grade students. All participants were male students between the ages of 15 to 16 years old. Since all participants were in the 9th grade, the language proficiency level of the participants was supposed to be an intermediate level which is expected to be at the high A2 level according to the CEFR.

\section{Data Collection Instrument}

Observation is a data collection instrument used to collect data about participants' behavior in a specific context. Creswell (2014) defined observation as "when the researcher takes field notes on the behavior and activities of individuals at the research site" (p. 239). The purpose of the observation is to study in-depth the many phenomena that 
constitute or affect the context of a unit (a student, a class, a school or a community) and develop generalizations about the larger population to which it belongs (Cohen et al., 2017).

In this study, the observation took place over four sessions, preceded by three training sessions to prepare the participants for the peer assessment practice and the proper use of the assessment checklist. Due to the COVID-19 pandemic, all sessions were conducted online using the Microsoft Teams platform. Prior to the start of the study, the participants were given a clear rationale for peer assessment. Moreover, the participants were explained the importance of peer assessment and the expected benefits that might be gained through it. Despite the observation being online, I was able to take many valuable notes that facilitated the interpretation of the data.

\section{Ethical Considerations}

In this study, many ethical protocols have been followed in order to preserve the confidentiality of the study. An approval was taken from the Ministry of Education to conduct this study in a public school. Due to all the participants being underage, voluntary informed consent has been obtained from their parents. For the anonymity and confidentiality of the participants, all of them have been given anonymous names. Moreover, the participants have been informed that all data gathered from the observation will be preserved for the purpose of the study and will not be disclosed to anyone.

\section{FINDINGS}

Observing the peer assessment process during the sessions enabled me to take notes about the students' negotiation and practice of peer assessment. During the first session, students asked each other several questions to clarify their writing works before assessing them. Although peer assessment instructions were clear for most of the participants, the researcher intervened many times to help low performing students and scaffold the peer assessment process. Due to scaffolding, the students gradually became more independent, but still needed some interventions from the researcher, especially to assist the lower-level students.

Participants were incredibly active and very helpful towards each other even though it was a new experience for them. To raise students' self-confidence, I encouraged them by using the word "teacher" to call each student, which had a great impact on them as they showed responsibility for assessing and grading each other's work. The peer assessment sessions were very helpful for the learning process and the students since they enhanced self-confidence, awareness, and responsibility as autonomous language learners. Moreover, the students were interested in assessing each other and passionately continued peer assessment sessions that positively changed the classroom atmosphere by engaging them in negotiations, such as asking, clarifying, assessing, and grading. Due to the element of scaffolding, discussions and negotiations with more knowledgeable students contributed to improved performance of lower-level proficiency students who somehow became more independent learners.

Since peer assessment has a social nature, we can't overlook the behavioral aspects of it. Although it was a new experience for them, all students maintained good behavior during the sessions. The turn-taking was systematic and smooth between them, and no misbehaviors or interruptions were noticed. Moreover, students were very polite and showed some respect to each other except for one aggressive case where one student rejected the criticism notes that were provided by his peer. Ultimately, it had a positive impact on the process by increasing the length of the negotiation and discussion between the two students.

In fact, there was a clear difference between the teacher's assessment and peer assessment in terms of classroom atmosphere, time spent on the tasks, teacher's workload, students' performance, and practice of the language. Peer assessment decreased the teachers' workload and helped them deal with the assessment process in a short time. Furthermore, peer assessment enhanced the students' attitude towards the writing class. They enjoyed the peer assessment sessions which made the writing class more appealing to them. Additionally, the conducive learning environment encouraged students to practice the language more freely, which is not the case in many writing classrooms in the Saudi EFL context. Finally, peer assessment has obviously enhanced classroom participation and actively engaged students into an effective cooperative learning.

In the final peer assessment session, the students were more actively involved in negotiation and discussion than the previous sessions. There was no intervention from the researcher except for facilitating the lower-level proficiency students who also showed very good self-confidence like higher-level proficiency students. Furthermore, their awareness and responsibility for assessment have remarkably increased. Additionally, students became more independent and confident as they could take many assessment notes even without referring back to the assessment checklist.

However, students' feedback focused on the lower-order concerns (LOCs) (sentence-level). No feedback regarding higher-order concerns (HOCs), such as organization, argument, and development were noticed. In terms of the amount of feedback produced by the students, it was very short and limited to the assessment checklist, but useful for peer assessment. It was observed that the amount and length of the feedback were significantly affected by the learners' varied proficiency levels. It was also noticed that some students, in particular the high performing students, outperformed their peers in the amount and length of the given feedback.

\section{DISCUSSION}


The objective of this study was to identify how students negotiate the practice of peer assessment in writing class. In order to answer this question, close observation was conducted during the peer assessment sessions to get a deeper understanding of the students' negotiation of peer assessment. Surprisingly, the close observation facilitated the process and helped students to actively participate in the peer assessment sessions. This finding supports the stance of Finn and Garner (2011) who advocate the idea of the observation during the peer assessment sessions for its potential advantages. The results are also in line with those previously published studies as the participants of this study were actively engaged in the writing class which was also reported by Hyland (2000), Grami (2010), and Yu et al. (2020). These results indicate that implementing ZPD can reduce the students' anxiety and lead to their effective participation in a writing class. Its implementation through discussion and negotiation can also push students to become more extroverted and more open to the learning process. Furthermore, many participants, in particular the low performing students, became more engaged in the learning process which is one of the key purposes of implementing the ZPD in the writing class.

Another important finding was that peer assessment had raised students' self-confidence, awareness, and responsibility towards assessment, which enhanced social interaction and negotiation among the students. Moreover, the participants were very much interested in assessing each other and passionate to have more peer assessment sessions. One assumption from the results is that when assessment tasks shift from teachers to the ESL/EFL student-writers, they will feel more confident and show some responsibility towards their learning. Moreover, they will be more aware of assessment criteria which encourage them to assess each other and implement those criteria to find their shortcomings. Additionally, implementing ZPD through peer assessment sessions helped turning students from being mere dependent learners to be more independent ones, which was evident in the third and fourth sessions in which the participants were able to provide effective and constructive feedback to their peers. Also, implementing ZPD had amazingly encouraged the hesitant students to be more confident which positively affected their participation in classroom activities. Moreover, ZPD created a good atmosphere for collaborative learning, which was evident in the students' participation and their enthusiasm for the peer assessment sessions. These findings support many previous studies, including Min (2005), Yang et al. (2006), Ertmer et al. (2007), Grami (2010), Moussaoui (2012), Yusof et al. (2012), Uymaz (2019).

Another finding of this study is that peer assessment has obviously decreased the teacher' workload and the time spent on assessment. Shifting responsibility of assessment to students made the main responsibilities of the teacher monitor, supervise, and facilitate the learning process for students which is one of the key aspects of student-centered classes and ZPD. This finding is in accordance with studies such as Yarrow \& Topping (2001).

One unanticipated finding from the observation showed that although the participants were young, they maintained good behavior during the peer assessment sessions. The sessions were very systematic, smooth, peaceful, and undisturbed in terms of turn taking, providing, or receiving feedback, and showing mutual respect to others. No interruption, rudeness, or misbehavior among the participants was noticed during the peer assessment sessions. Moreover, the students were provided effective and useful feedback and no friendship-bias was noticed during these sessions. One assumption from these findings is that shifting the responsibility of the assessment tasks to the students made them feel more responsible for their own learning, which was positively reflected in their attitude and behavior in the class. Such a finding was also reported by Liu and Carless (2006). However, this result is contrary to some previous studies, such as Saito and Fujita (2004), and Lee et al. (2013) who claim that students can have the tendency of a friendship-bias during a peer review due to the relationship between them. Students who are less responsible might also have a tendency of friendship bias, which might affect the assessment process.

One interesting finding is that students during the negotiation were focused on the lower-order concerns (LOCs), such as structure, capitalization, space between words, handwriting, grammar, spelling, and punctuations (sentencelevel only), which is in line with the study by Storch (2005). The reason behind that in my opinion, is the lower level of language proficiency of the students which made them stick to the assessment checklist, i.e., their limited linguistic competence does not help them to look beyond the sentence level and think more critically.

In terms of practicing the targeted language, observation showed that the amount of practice had significantly risen. This result makes it possible to assume with confidence that the implementation of ZPD theory through peer assessment gave the students more opportunities to negotiate and discuss which expanded their practicing of the new language and positively affected their language acquisition. This result may also be explained by the fact that learning is socially constructed through social activities, such as interaction, negotiation, and collaboration. This result is in line with studies by Min (2005) and Lundstrom and Baker (2009).

Observation also showed that the dynamic nature of the peer assessment sessions which depends on giving and receiving feedback at the same time expanded the participants' time of speaking which forced them to speak for a longer period to discuss, negotiate and justify their points of view. It is possible to assume that implementing ZPD through dynamic peer assessment sessions had contributed to the learners' participation, negotiation, engagement, and openness, and enabled them to be more confident and more autonomous students.

Observation also showed a need for more peer assessment training as it is a new experience for students, and they need more practice to obtain the necessary skills for assessing their peers' works. This result may suggest that the students are neither aware of the assessment criteria nor its literacy which are essential for the assessment process. Moreover, students in the Saudi EFL context are accustomed to the teacher's feedback and do not consider it a role of 
the inexperienced students. Therefore, peer assessment training sessions have to take place before shifting the responsibility of assessment to the students. As this finding was expected, it supports several previous studies by Stanley (1992), Zhu (1995), Hansen and Liu (2005), and Min (2005, 2006) who also emphasized the significant role of training learners before conducting peer assessment sessions in classrooms.

\section{CONCLUSION}

This research project provided a deeper insight and shed new light on the implementation of peer assessment and ZPD in writing classes. The key findings of the study suggest that peer assessment is a very effective tool and has a great impact on EFL Students' attitudes towards writing classes in the Saudi context. It incredibly contributes to triggering the spirit of competition and teamwork among students in a writing class through a collaborative learning approach. Peer assessment also raises students' motivation, confidence, responsibility, and awareness of the writing assessment criteria which lead to significant improvements in their writing skills.

Negotiation and interaction as a social practice in writing peer assessment sessions have the potential to stimulate the social nature of the learning between low performing individuals and the more knowledgeable ones, which contributes to revealing their writing shortcomings and enables them to correct those shortcomings and show better writing performances.

Considering the pedagogical implications for this project, this study might be a valuable source for many stakeholders. Furthermore, it provides some directions for future studies to add more valuable findings which might help create a broader view and a deeper understanding of alternative and peer assessment.

\section{REFERENCES}

[1] Alqurashi, F. (2009). Saudi students' reactions to peer response groups in EFL composition classrooms. Journal of King Saud University - Languages and Translation, 21, 57-67.

[2] Alshakhi, A. (2018). Revisiting the writing assessment process at a Saudi English language institute: Problems and solutions. English Language Teaching, 12(1), 176. https://doi.org/10.5539/elt.v12n1p176

[3] Alshakhi, A. (2019). Assessing the writing assessment. The perception of Saudi graduate EFL learners: A case study. Arab World English Journal, Special Issue 1: Application of Global ELT Practices in Saudi Arabia. 87-102. https://dx.doi.org/10.24093/awej/elt1.7

[4] Bahanshal, D. A. (2013). The effect of large classes on English teaching and learning in Saudi secondary schools. English Language Teaching, 6(11), 49-59.

[5] Bijami, M., Kashef, S. H., \& Nejad, M. S. (2013). Peer feedback in learning English writing: Advantages and disadvantages. Journal of Studies in Education, 3(4), 91-97.

[6] Black, P. \& William, D. (1998). Assessment and classroom learning. Assessment in Education: Principles, Policy \& Practice, 5(1), 7-74. https://doi.org/10.1080/0969595980050102

[7] Cohen, L., Manion, L., \& Morrison, K. (2017). Research methods in education. Routledge. UK.

[8] Conrad, S. M., \& Goldstein, L. M. (1999). ESL student revision after teacher-written comments: Text, contexts, and individuals. Journal of Second Language Writing, 82(2), 147-179.

[9] Coombe, C., Troudi, S., \& Al-Hamly, M. (2012). Foreign and second language teacher assessment literacy: Issues, challenges and recommendations. In language teaching and learning in ESL education.

[10] Creswell, J. (2014). Research design. Sage publications. UK.

[11] Crusan, D. (2002). An assessment of ESL writing placement assessment. Assessing Writing, 8(1), 17-30.

[12] Elyas, T., \& Al Grigri, W. H. (2014). Obstacles to teaching English in Saudi Arabia public schools: Teachers' and supervisors' perceptions. International Journal of English Language Teaching, 2(3), 74-89.

[13] Ertmer, P.A., Richardson, J.C., Belland, B., Camin, D., Connolly, P., Coulthard, G., Lei, K. \& Mong, C. (2007). Using peer feedback to enhance the quality of student online postings: An exploratory study. Journal of Computer-Mediated Communication, 12, 412-433. https://doi.org/10.1111/j.1083-6101.2007.00331.x

[14] Finn G.M., \& Garner, J. (2011). Twelve tips for implementing a successful peer assessment. Medical Teacher, 33(6), 443-446. https://doi.org/10.3109/0142159X.2010.546909

[15] Grami, G. M. A. (2010). The effects of integrating peer feedback into university-level ESL writing curriculum: A comparative study in a Saudi context (Unpublished doctoral dissertation). Newcastle University, retrieved from http://theses.ncl.ac.uk/jspui/handle/10443/933 retrieved on 30th March 2021.

[16] Hamp-Lyons, L. (1990). Second language writing: Assessment issues. Second language writing: Research insights for the classroom, 1, 69-87.

[17] Hansen, J. G., \& Liu, J. (2005). Guiding principles for effective peer response. ELT journal, 59(1), 31-38.

[18] Huang, J. (2009). Factors affecting the assessment of ESL students' writing. International Journal of Applied Educational Studies, 5(1), 112-119.

[19] Huisman, B., Saab, N., van Driel, J., \& van den Broek, P. (2018). Peer feedback on academic writing: Undergraduate students' peer feedback role, peer feedback perceptions and essay performance. Assessment \& Evaluation in Higher Education, 43(6), 955-968. https://doi.org/10.1080/02602938.2018.1424318

[20] Hyland, K. (2019). Second language writing. Cambridge university press. UK.

[21] Hyland, F. (2000). ESL writers and feedback: Giving more autonomy to students. Language Teaching Research, 4(1), 33-54. https://doi.org/10.1177/136216880000400103

[22] Khaliliaqdam, S. (2014). ZPD, scaffolding and basic speech development in EFL context. Procedia-Social and Behavioral Sciences, 98, 891-897. 
[23] Knoch, U. (2011). Rating scales for diagnostic assessment of writing: What should they look like and where should the criteria come from? Assessing Writing, 16(2), 81-96.

[24] Kramsch, C. (1986). From language proficiency to interactional competence. The modern language journal, 70(4), 366-372.

[25] Krashen, S. (1982). Principles and practice in second language acquisition. Pergamon Press Inc. California, USA.

[26] Lee, C.J., Sugimoto, C.R., Zhang, G. and Cronin, B. (2013). Bias in peer review. Journal of the American Society for Information Science and Technology, 64, 2-17. https://doi.org/10.1002/asi.22784

[27] Liu, N. \& Carless, D. (2006). Peer feedback: The learning element of peer assessment. Teaching in Higher Education, 11, 279290. https://doi.org/10.1080/13562510600680582

[28] Lundstrom, K. \& Baker Smemoe, W. (2009). To give is better than to receive: The benefits of peer review to the reviewer's own writing. Journal of Second Language Writing, 18, 30-43. https://doi.org/10.1016/j.jslw.2008.06.002

[29] Min, H. T. (2005). Training students to become successful peer reviewers. System, 33(2), 293-308. https://doi.org/10.1016/j.system.2004.11.003

[30] Min, H. T. (2006). The effects of trained peer review on EFL students' revision types and writing quality. Journal of second language writing, 15(2), 118-141.

[31] Min, H. T. (2016). Effect of teacher modeling and feedback on EFL students' peer review skills in peer review training. Journal of Second Language Writing, 31, 43-57.

[32] Moussaoui, S. (2012). An Investigation of the effects of peer evaluation in enhancing Algerian student's writing autonomy and positive affect. Procedia - Social and Behavioral Sciences, 69, 1775-1784. https://doi.org/10.1016/j.sbspro.2012.12.127

[33] Obeid, R. (2017). Second language writing and assessment: Voices from within the Saudi EFL context. English Language Teaching, 10(6), 174-181.

[34] Saito, H., \& Fujita, T. (2004). Characteristics and user acceptance of peer rating in EFL writing classrooms. Language Teaching Research, 8(1), 31-54.

[35] Stanley, J. (1992). Coaching student writers to be effective peer evaluators. Journal of second language writing, 1(3), $217-233$.

[36] Storch, N. (2005). Collaborative writing: Product, process, and students' reflections. Journal of Second Language Writing, 14, 153-173. https://doi.org/10.1016/j.jslw.2005.05.002

[37] Tannenbaum, J. E. (1996). Practical ideas on alternative assessment for ESL students. ERIC Digest. 1, 1-8.

[38] Urmeneta, C. E., \& Walsh, S. (2017). Classroom interactional competence in content and language integrated learning. Applied linguistics perspectives on CLIL, 1, 183-200.

[39] Uymaz, E. (2019). The effects of peer feedback on the essay writing performances of EFL students. International Journal of Curriculum and Instruction, 11(2), 21-37.

[40] Vygotsky, L. S. (1978). Mind in society: The development of higher psychological processes. Harvard university press. USA.

[41] Walsh, S. (2011). Exploring classroom discourse: Language in action. Taylor \& Francis. UK.

[42] Walsh, S. (2013). Classroom discourse and teacher development. Edinburgh University Press. UK.

[43] Walsh, S. (2014). Developing classroom interactional competence. Language Issues: The ESOL Journal, 25(1), 4-8.

[44] Wertsch, J. V. (1984). The zone of proximal development: Some conceptual issues. New Directions for Child and Adolescent Development, 1984(23), 7-18.

[45] Yang, M., Badger, R., \& Yu, Z. (2006). A comparative study of peer and teacher feedback in Chinese EFL writing class. Journal of Second Language Writing, 15, 179-200. https://doi.org/10.1016/j.jslw.2006.09.004

[46] Yarrow, F. \& Topping, K. (2001). Collaborative writing: The effects of metacognitive prompting and structured peer interaction. The British Journal of Educational Psychology, 71(2), 261-82. https://doi.org/10.1348/000709901158514

[47] Yu, S., Jiang, L., \& Zhou, N. (2020). The impact of L2 writing instructional approaches on student writing motivation and engagement. Language Teaching Research. https://doi.org/10.1177/1362168820957024

[48] Yusof, J., Ab manan, N., \& Alias, A. (2012). Guided peer feedback on academic writing tasks using Facebook notes: An exploratory study. Procedia - Social and Behavioral Sciences, 67, 216-228.

[49] Zhu, W. (1995). Effects of training for peer response on students' comments and interaction. Written Communication, 12(4), 492-528.

Talal Mohammed Alqarni has a Bachelor of English language, King Abdelaziz University, Jeddah, Saudi Arabia 2010. He received his master's degree in TESOL, King Abdelaziz University, Jeddah, Saudi Arabia, in 2021. With particular research interests in language testing and assessment, writing assessment.

$\mathrm{He}$ is an EFL Teacher at the Ministry of Education in Jeddah, Saudi Arabia. He is also a member of the students' Advisory Committee for the Development of Post Graduate Programs, King Abdelaziz University, Jeddah, Saudi Arabia.

Abdullah Mohammed Alshakhi is an Associate Professor of Applied Linguistics and the Head of Curriculum and Testing Unit at the English Language Institute at King Abdulaziz University. With particular research interests in language testing and assessment literacy, construct validity, writing assessment, and language policy.

$\mathrm{He}$ has published in both local and international journals. He is actively involved in several workshops involving language assessment and testing through the Educational Testing Service (ETS), Cambridge Assessment, and the European Association of Language Testing and Assessment (EALTA). 